ARTICLE

DOI: $10.1038 / s 41467-018-03353-2$

\title{
Dark zone of the Greenland Ice Sheet controlled by distributed biologically-active impurities
}

\author{
Jonathan C. Ryan 1,2,3, Alun Hubbard ${ }^{1,4}$, Marek Stibal ${ }^{5,6}$, Tristram D. Irvine-Fynn ${ }^{1}$, Joseph Cook (1) ${ }^{7}$, \\ Laurence C. Smith ${ }^{2}$, Karen Cameron (1) ${ }^{8}$ \& Jason Box ${ }^{9}$
}

\begin{abstract}
Albedo-a primary control on surface melt-varies considerably across the Greenland Ice Sheet yet the specific surface types that comprise its dark zone remain unquantified. Here we use UAV imagery to attribute seven distinct surface types to observed albedo along a $25 \mathrm{~km}$ transect dissecting the western, ablating sector of the ice sheet. Our results demonstrate that distributed surface impurities - an admixture of dust, black carbon and pigmented algaeexplain $73 \%$ of the observed spatial variability in albedo and are responsible for the dark zone itself. Crevassing and supraglacial water also drive albedo reduction but due to their limited extent, explain just 12 and $15 \%$ of the observed variability respectively. Cryoconite, concentrated in large holes or fluvial deposits, is the darkest surface type but accounts for $<1 \%$ of the area and has minimal impact. We propose that the ongoing emergence and dispersal of distributed impurities, amplified by enhanced ablation and biological activity, will drive future expansion of Greenland's dark zone.
\end{abstract}

\footnotetext{
${ }^{1}$ Centre for Glaciology, Department of Geography and Earth Sciences, Aberystwyth University, Aberystwyth SY23 3DB, UK. ${ }^{2}$ Department of Geography, University of California, Los Angeles, Los Angeles, CA 90095, USA. ${ }^{3}$ Institute at Brown for Environment and Society, Brown University, Providence, RI 02906, USA. ${ }^{4}$ Centre for Arctic Gas Hydrate, Environment and Climate, Department of Geology, University of Tromsø, 9037 Tromsø, Norway. ${ }^{5}$ Department of Ecology, Faculty of Science, Charles University, 12844 Prague, Czech Republic. ${ }^{6}$ Department of Geochemistry, Geological Survey of Denmark and Greenland, 1350 Copenhagen, Denmark. ${ }^{7}$ Department of Geography, University of Sheffield, Sheffield S10 2TN, UK. ${ }^{8}$ Institute of Biological, Environmental and Rural Sciences, Aberystwyth University, Aberystwyth SY23 3DB, UK. ${ }^{9}$ Department of Glaciology and Climate, Geological Survey of Denmark and Greenland, 1350 Copenhagen, Denmark. Correspondence and requests for materials should be addressed to A.H. (email: abh@aber.ac.uk)
} 
T he Greenland Ice Sheet has become the largest cryospheric contributor to global sea-level rise predominantly through increased surface melt and runoff, which accounts for over half of its mass loss since $1991^{1-4}$. The dominant energy source for snow and ice melt is direct solar shortwave radiation, the absorption and reflection of which is predominantly modulated by surface albedo ${ }^{5-7}$. Accurately constraining spatiotemporal patterns of albedo across the ice sheet is hence fundamental to understanding and predicting surface melt and runoff along with their impact on ice sheet flow dynamics and sea-level rise. A conspicuous feature of Greenland's ablation area is its dark zone, an area of bare ice with particularly low albedo that appears across the west and southwest sectors of the ice sheet each summer $^{8-10}$. At the Arctic Circle, in the vicinity of the Kangerlussuaq (K-) sector, the dark zone extends between 20 and $75 \mathrm{~km}$ from the land-terminating margin where Moderate Resolution Imaging Spectroradiometer (MODIS) data indicate a regional albedo minimum of $\sim 0.34^{8}$. From 2000 to 2012 , the spatial extent of the dark zone increased by $12 \%$ but also exhibited considerable interannual variability ${ }^{11,12}$. The extent of the dark zone is weakly positively correlated with air temperature and negatively correlated with solar radiation during June, July and August (JJA $)^{11,12}$. This suggests that the ongoing albedo decrease observed during the melt season is not simply driven by melting of the winter snowpack to reveal the darker bare ice surface beneath, but, following exposure, there are changes in the nature of the bare ice itself $^{11,12}$. However, the surface characteristics of the dark zone remain unquantified because the spatial resolution of satellite imagery is insufficient to fully resolve the specific surface types that comprise it, and how these surfaces evolve through time, distinguishing the dark zone from brighter ice surfaces adjacent to it.

Previous field-based, in situ observations indicate that western Greenland's ablation zone is characterized by highly variable nonice constituents and surface structures $8,13-15$. These include features such as crevasses, fractures and foliations ${ }^{16,17}$; supraglacial hydrological features, including streams, rivers, ponds and lakes ${ }^{18,19}$; snow patches and fracture cornices; cryoconite, concentrated in holes or in supraglacial fluvial deposits ${ }^{20,21}$; microbes and their humic by-products ${ }^{22-24}$; mineral dust and aerosols from outcropping or contemporary aeolian deposition including black carbon from wildfires ${ }^{10,25,26}$ and other aerosols. While the highest resolution optical satellite imagery currently available has facilitated the examination of crevasse fields ${ }^{16}$ and surficial hydrology ${ }^{19}$, a quantitative assessment of the specific ice surface types that comprise the dark zone, and how they combine to yield observed albedo patterns across the ablation zone of the ice sheet, has yet to be made.

Here, we utilize high-resolution ( $15 \mathrm{~cm}$ pixel size) imagery acquired from an unmanned aerial vehicle (UAV) to characterize the specific ice surfaces across the dark zone and determine their impact on the mesoscale $(1-10 \mathrm{~km})$ albedo distribution during peak melt season, as represented by the MODIS albedo product, MOD10A1. On 8 August 2014, a fixed-wing UAV equipped with a digital camera and upward and downward facing pyranometers was deployed from a field camp based in the vicinity of the Ktransect, S6 automated weather station (AWS) on a $25 \mathrm{~km}$ eastwest transect dissecting the dark zone (Fig. 1). Seven distinct surface types were visually identified on the ground by an expert and automatically classified based on their reflectance and roughness properties. The survey transect was divided into sixty $500 \times 500 \mathrm{~m}$ segments, co-located to the footprints of corresponding MODIS pixels, and the fractional area of each surface type in each segment was determined using a supervised knearest neighbours (k-NN) classification (see Methods section: Surface Classification for more information) (Figs. 1, 2). Finally, the mean albedo of each surface type was derived from the digital imagery and the relative contribution of different surface types to mesoscale albedo variability (defined by MOD10A1 pixels) was calculated using principal component regression (PCR).

\section{Results}

Surface type variation along the transect. Analysis of all UAV imagery allowed us to visually identify and automatically classify seven distinct surface types across the survey transect: (i) clean ice, (ii) ice containing uniformly distributed impurities, (iii) deep water, (iv) shallow water, (v) cryoconite either in holes or fluvial deposits, (vi) crevasses and (vii) snow (Fig. 3). Distinction between clean ice and ice containing uniformly distributed impurities was guided by qualitative assessment of 112 oblique and nadir photographs taken from the ground $(<1 \mathrm{~cm}$ pixel footprint) at specific study sites around the field camp (Fig. 1). These images confirm that distributed impurities across the ice surface are responsible for bare ice albedo variability at the local scale $(1-10 \mathrm{~m})$ (Fig. 4). In order to upscale and understand the impact of these surface impurities on the mesoscale albedo distribution of the ablation zone, we divided bare ice into two categories: clean ice, with very low impurity concentrations, and ice containing some or an abundance of impurities. It is apparent that additional categories could be defined for bare ice given sufficiently high pixel resolution, but for the purpose of this study, and considering the spectral limitations of the onboard camera, we do not attempt to. We note that it would be a fruitful direction with multi- and hyper-spectral sensor payloads. Clean ice has $57.2 \%$ aerial coverage in the lower, western half of the survey transect between 0 and $17 \mathrm{~km}$ (Fig. 3). In the eastern half (17-27 $\mathrm{km})$, clean ice coverage is lower at $23.0 \%$. Ice containing uniformly distributed impurities (Fig. 5a) varies inversely to clean ice, with a higher fraction in the eastern half $(74.5 \%)$ compared to the western half of the transect (40.0\%) (Fig. 3).

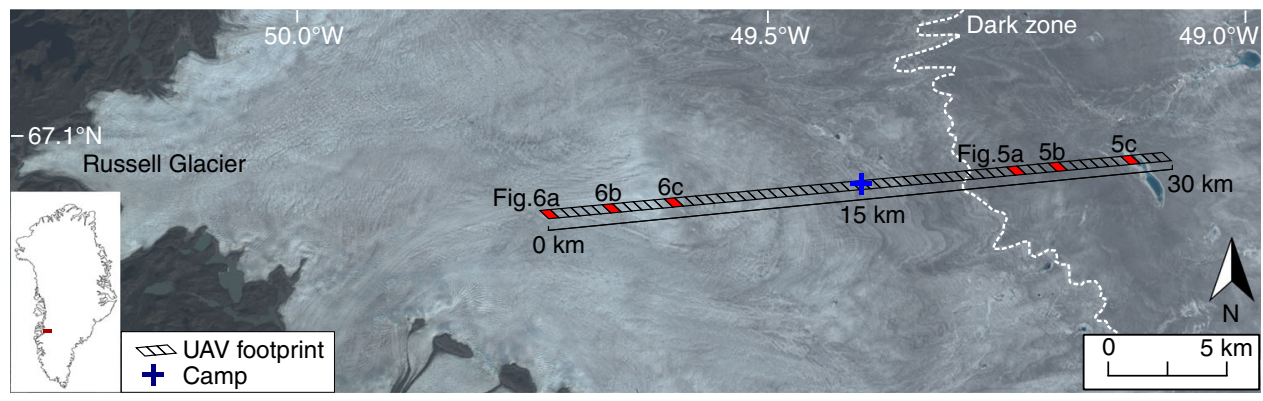

Fig. 1 Overview map showing location of UAV survey transect. The background is a Landsat 8 Operational Land Imager (OLI) true colour image of the Kangerlussuaq sector of the Greenland Ice Sheet from 6 August 2014. The transect was divided into sixty $0.25 \mathrm{~km}^{2}$ segments for comparison with the MODIS albedo product, MOD10A1. High-resolution aerial imagery and surface classification of six segments (coloured red) are shown in Figs. 5 and 6 


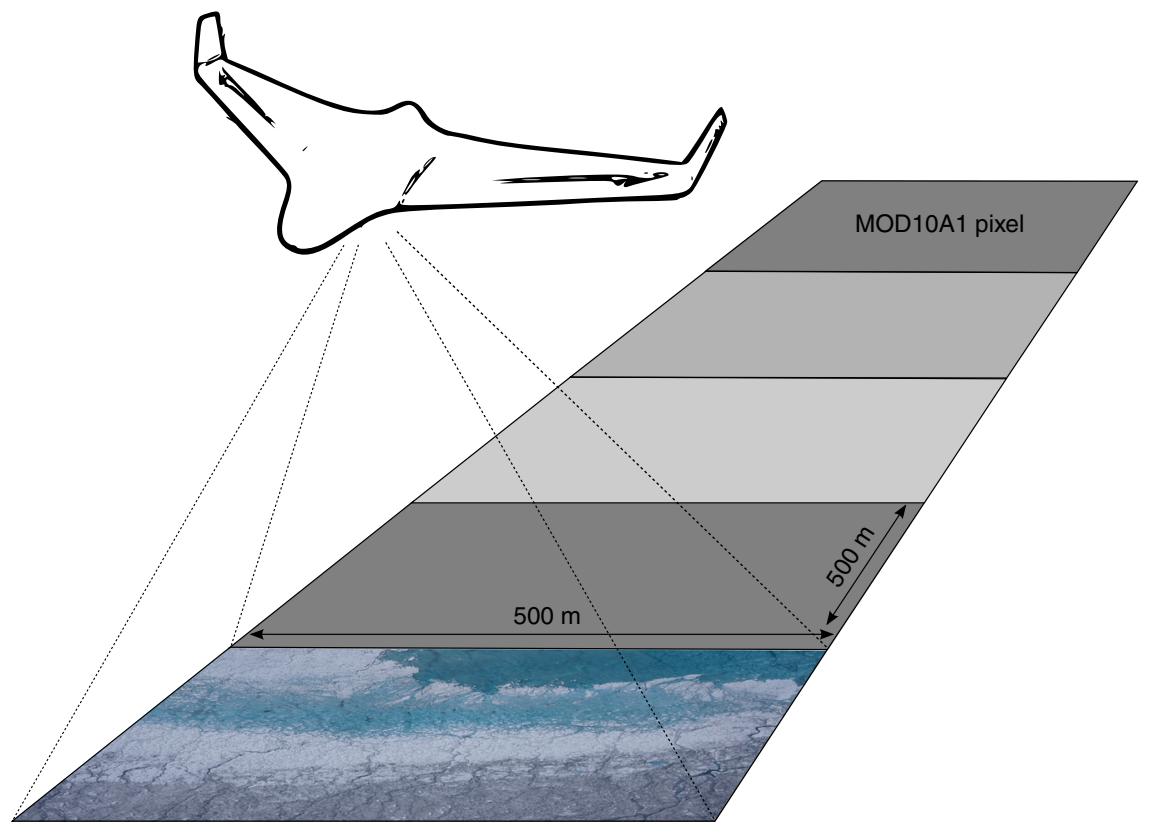

Fig. 2 Schematic summarizing the aims of the study. Aerial digital imagery are used to characterize the surface types that are found in the ablation zone and assess their impact on mesoscale spatial albedo patterns as represented by MODIS

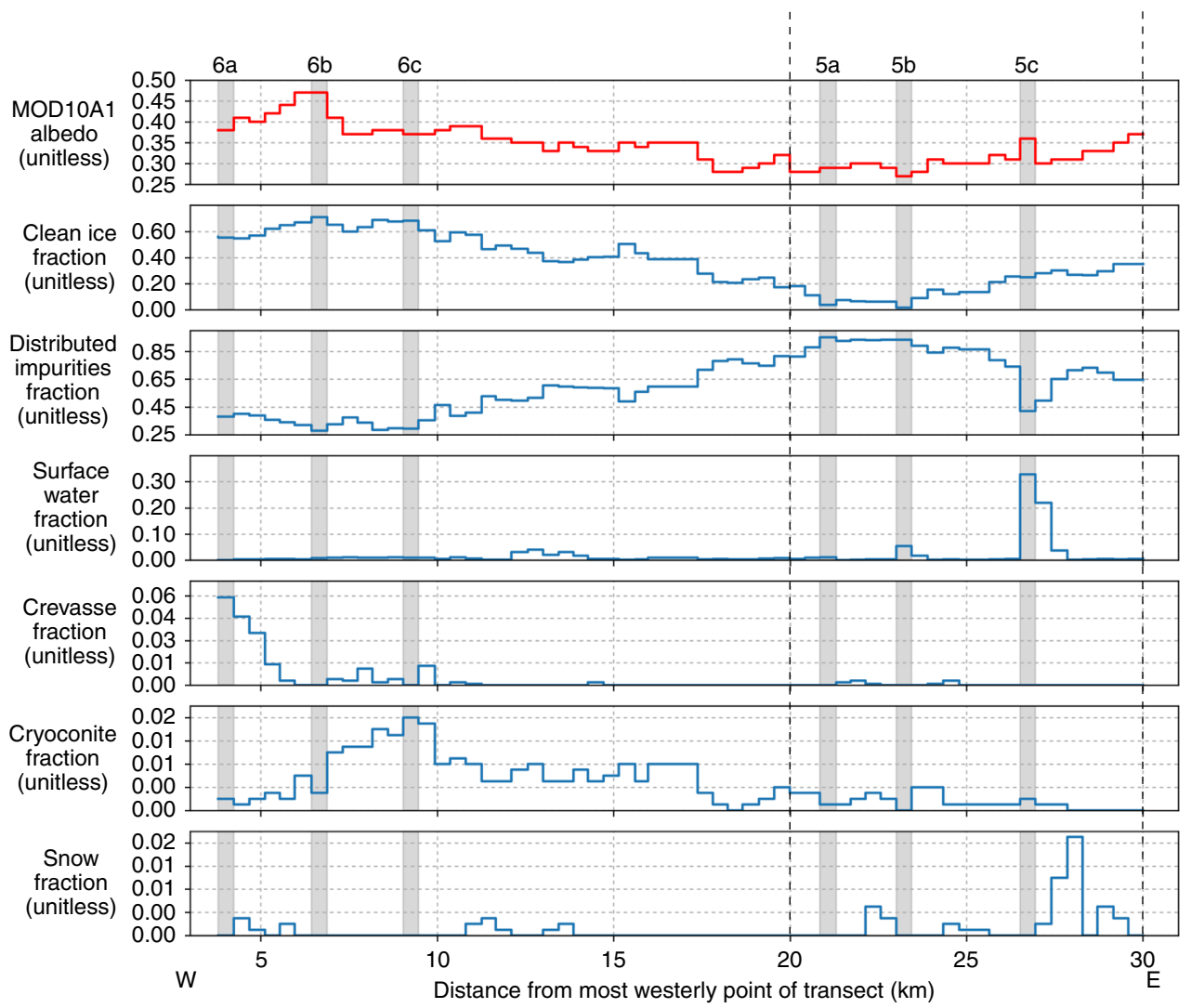

Fig. 3 Variation of albedo and the fractional area of each surface type across the UAV transect. The albedo and fractional areas derived from MOD10A1 and the UAV imagery, respectively, on 8 August 2014. The $x$ axis is displayed in Fig. 1. The results of the classification for six segments, highlighted by the vertical grey bars, are shown in Figs. 5 and 6

Cryoconite is commonly found in holes but also in fluvial deposits near supraglacial streams and lakes (Fig. 6c). In this study, cryoconite is distinguished from ice containing distributed impurities by its very low albedo, which is indicative of concentrated, rather than distributed, impurities. Cryoconite has a maximum aerial coverage of $1.6 \%$ at $8 \mathrm{~km}$ from the western end of the transect and a mean coverage of $0.6 \%$ across the entire transect (Fig. 3). It is possible that we underestimate the fractional 

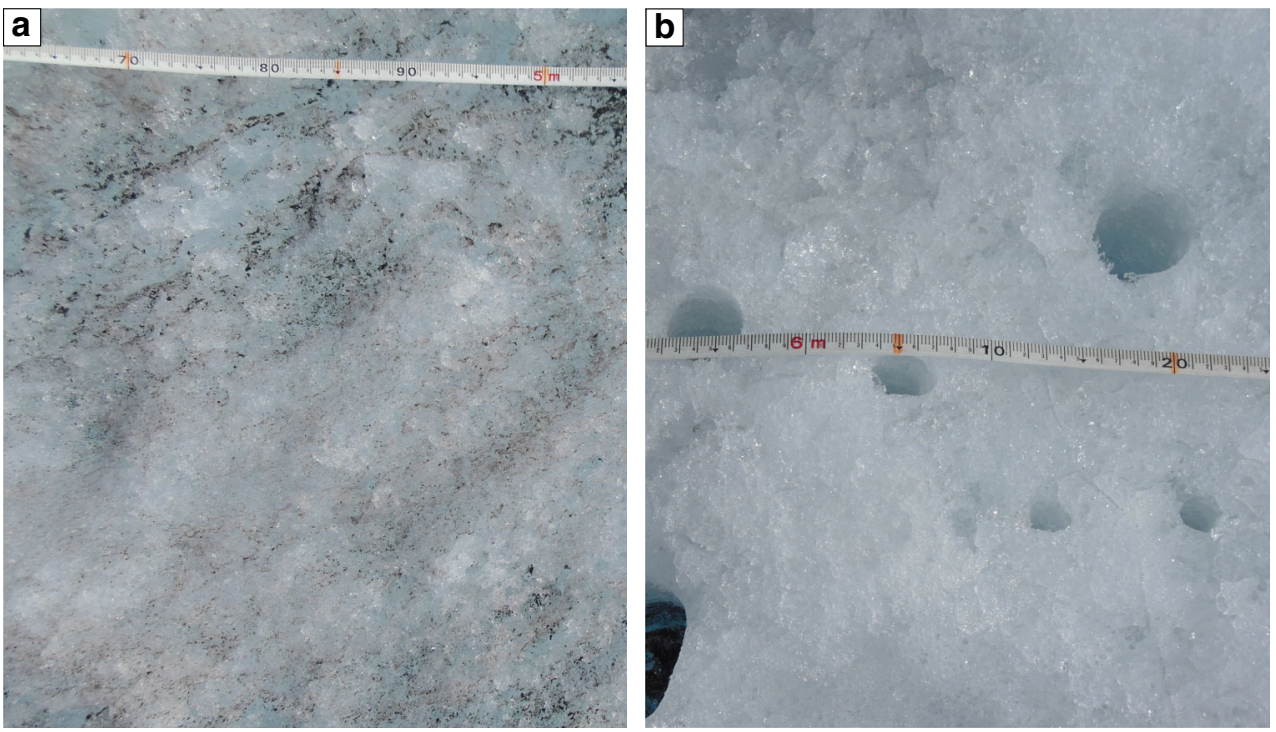

Fig. 4 Photograph showing close-up of bare ice found in the ablation zone. The photographs were taken near the field camp located close to the S6 automated weather station at $1000 \mathrm{~m}$ a.s.l. (Fig. 1). a Ice containing distributed impurities on the surface and $\mathbf{b}$ clean ice with cryoconite holes

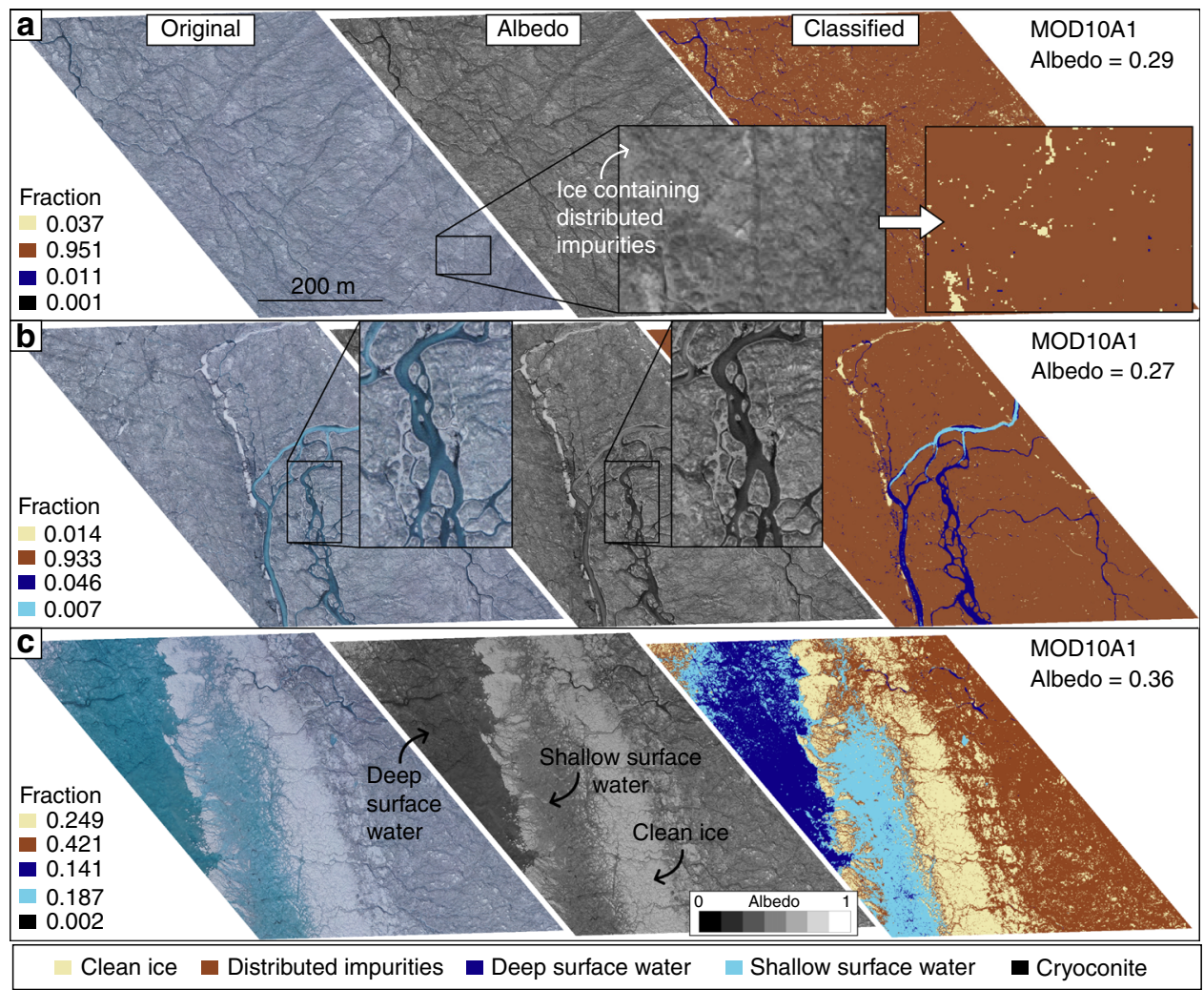

Fig. 5 RGB digital image, albedo map and classification of surface types in three MOD10A1 pixels. The albedo maps were derived from the digital images (Methods). The locations of the segments along the UAV transect are shown in Fig. 1. a Segment characterized by mostly ice containing uniformly distributed impurities. b Segment characterized by similar ice surface to a but with a larger fraction of channelized surface melt-water. c Segment dominated by a supraglacial lake with a previous shore consisting of clean ice

area of small cryoconite holes due to the limited, $15 \mathrm{~cm}$ pixel resolution of our UAV imagery. However, we note that smaller cryoconite holes $(<15 \mathrm{~cm})$ would also be hidden from virtually all aerial and satellite imagery obtained at low solar elevation angles. Furthermore, cryoconite hole depths tend to equilibrate as the melt season progresses, due to their low albedo and preferential radiative absorption in comparison to brighter ice surfaces surrounding them ${ }^{20,21}$. Coincident field measurements, made during UAV image acquisition, indicate that the cryoconite holes observed in our study were well developed. The implication is that once they have attained equilibrium depth, they cease to absorb additional energy (which would make them deeper) compared to surrounding ice and hence are effectively neutralized from the effects of incoming solar radiation. For these reasons, we 


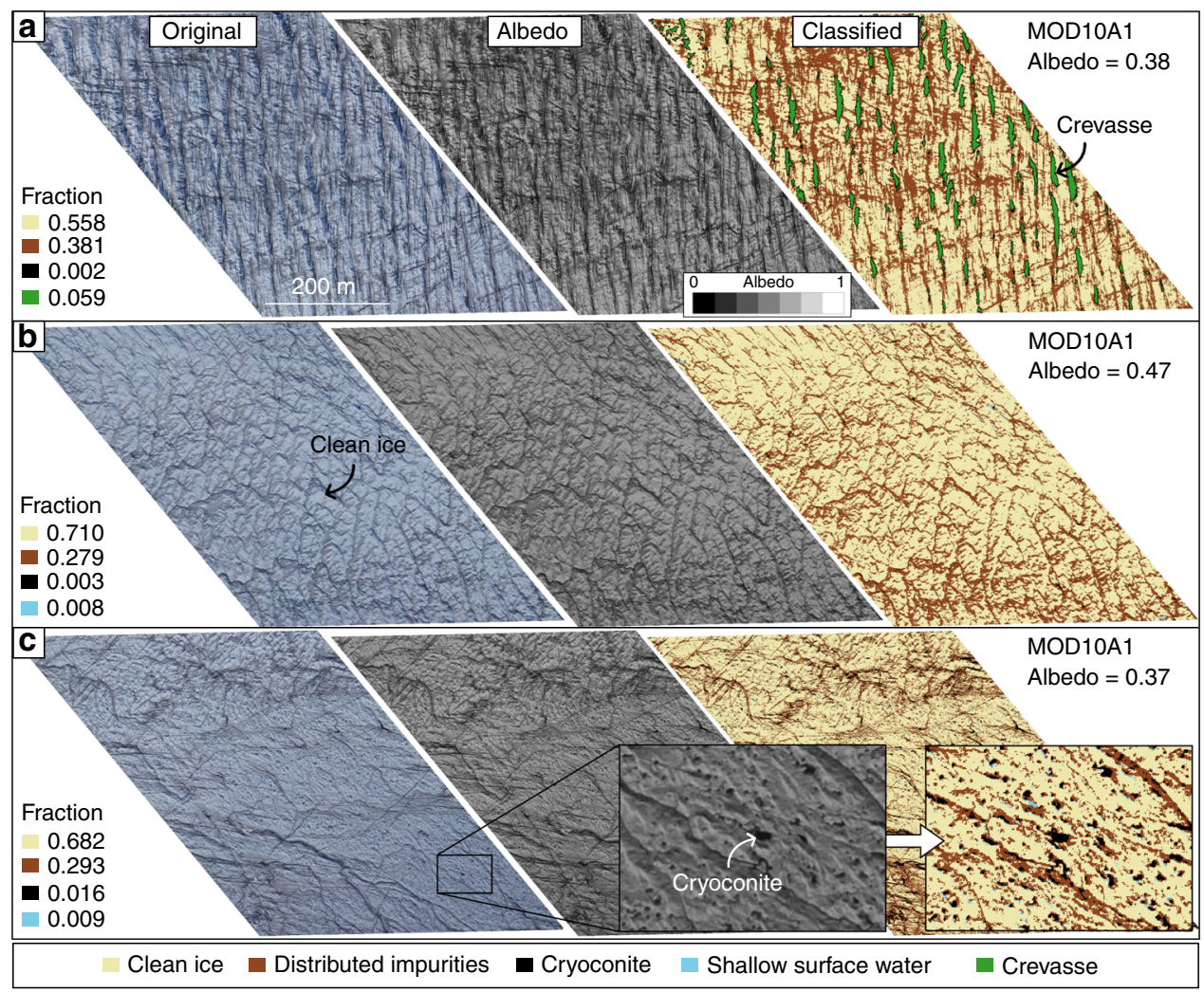

Fig. 6 RGB digital image, albedo map and classification of surface types in three more MOD10A1 pixels. The albedo maps were derived from the digital images (Methods). The locations of the segments along the UAV transect are shown in Fig. 1. a Segment containing a high fraction of crevasses. $\mathbf{b}$ Segment characterized by a much lower relief surface and no crevasses. c Segment characterized by clean ice and numerous cryoconite holes

argue that smaller cryoconite holes had a minimal net impact on MODIS-derived albedo compared to the ice surface surrounding them.

At $23 \mathrm{~km}$ (all distances refer from the western start point of the UAV transect), a braided meltwater channel network with a fractional area of $5.3 \%$, intersects the transect (Figs. 1 and $5 \mathrm{~b}$ ), but otherwise, surface water comprises only $1.9 \%$ of the survey area (Fig. 3). These results are consistent with Smith et al. ${ }^{19}$ who found that surface water accounted for $1.4 \%$ of a $\sim 5000 \mathrm{~km}^{2}$ bare ice area in the K-sector of the ice sheet. At $28 \mathrm{~km}$, a small, $0.83 \mathrm{~km}^{2}$ supraglacial lake covers $32.8 \%$ of the segment (Fig. $5 \mathrm{c}$ ). Crevasse density is highest on the western flank between 2 and $5 \mathrm{~km}$ and attains maximum coverage of $5.9 \%$ at $2 \mathrm{~km}$ (Figs. 3, 6a). Upglacier of $10 \mathrm{~km}$, crevasses are almost entirely absent (Fig. 6b). Remnant snow patches, which persist within ice fractures and supraglacial channel incisions, attain a maximum coverage of $1.7 \%$ with a mean aerial coverage of only $0.1 \%$, at this time of year.

Relationship between surface types and albedo patterns. The mesoscale albedo distribution, determined from MOD10A1 data, exhibits considerable variability along the survey transect with values between 0.27 and 0.47 (Figs. 1, 3). The dark zone, which is approximately located between 18 and $27 \mathrm{~km}$ along the survey transect, has a mean albedo of 0.29 and is characterized by distinct and conspicuous banding that specifically relate to foliation structures apparent in Landsat 8 imagery (Fig. 1). Between 80 and $95 \%$ of the dark zone is classified as ice containing uniformly distributed impurities (mean albedo $(\alpha)=0.27$ ), with the remaining 5-20\% consisting of predominately clean ice (mean $\alpha$ $=0.55$ ) (Fig. 5a). Application of PCR reveals that the fractional area of ice containing uniformly distributed impurities explains $73 \%$ of the observed mesoscale albedo variability. Although not the darkest surface type observed, distributed impurities dominate the mesoscale albedo signal due to their extensive coverage and large variations in their fractional area across the survey transect. Distributed impurities have been attributed to the outcropping of aeolian dust deposited during the early Holocene $e^{, 10,27}$ and/or pigmented surface algal blooms and associated humic material ${ }^{22-24}$.

Locally, defined at the scale of a single MODIS pixel, supraglacial water, contained in both lakes and channels, has a distinct impact on albedo due to its low albedo $(\alpha=0.19-0.26)$. The segment of the transect that corresponds to a large braided channel network at $23 \mathrm{~km}$ has an albedo of 0.28 (Fig. 5b). This is $\sim 0.02$ lower than the surrounding segments with $<1 \%$ surface water yet are otherwise composed of similar ice surfaces (Figs. 3, 5a). However, in comparison to distributed impurities, supraglacial water has a minor impact on the mesoscale albedo pattern and explains only $15 \%$ of the albedo variability across our survey transect. Surprisingly, the supraglacial lake located at $28 \mathrm{~km}$ is not associated with a significant reduction of MOD10A1 albedo. This is because it is relatively narrow (260 m width) and covers just $33 \%$ of the segment, while $25 \%$ of the remaining segment consists of very bright clean ice faculae (mean $\alpha=0.58$ ): interpreted as a shoreline exposed when the lake level dropped (Fig. 5c). Hence, the low albedo of the lake water (mean $\alpha=0.19$ ) itself is offset by the brightness of the surrounding ice surface adjacent to it yielding minimal change in the net albedo (MOD10A1) signature.

Crevassing explains $12 \%$ of albedo variability and its impact is well illustrated at 3-4 km where a transition into a crevasse zone yields a significant reduction in mesoscale albedo compared to the adjacent, flatter surface (Fig. 6a, b). Crevasses enhance shortwave 
radiation absorption; radiative transfer modelling indicates that the presence of crevasses can double the downward energy absorbed relative to a homogeneous, flat ice surface and reduce albedo by between 0.10 and $0.25^{28,29}$. The amount of radiation absorbed by crevasses is determined by their size, orientation, density and whether they are water-filled. One of the most densely crevassed areas across the transect (5.9\% fractional area) (Fig. 6a), with crevasse widths up to $\sim 10 \mathrm{~m}$ and depths in excess of $8 \mathrm{~m}$, yields an albedo reduction of $\sim 0.06$ in comparison to the segment in Fig. 6b, which has no crevassing but similar fractions of other surface types (Figs. 3, 6b). Elsewhere, at 6-7 km, smaller crevasses, with mean widths of $5 \mathrm{~m}$, have a reduced impact on mesoscale albedo, lowering it by only 0.02 in comparison to the control segment in Fig. 6b. This observation is at odds with radiative transfer modelling results because the modelled crevasses were compared against a flat, clean ice surface, which is not the case here (Fig. 6b) ${ }^{28}$. Cathles et al. ${ }^{29}$ modelled crevasses with width to depth ratios similar to the crevasses we observed and found that they have a melt enhancement factor of 1.14-1.20 at solar zenith angles of $45^{\circ}$, which is in broad agreement with our findings.

Increases in the fractional area of cryoconite, either in large holes or fluvial deposits, are not particularly associated with mesoscale albedo reduction across the survey transect, and surprisingly, the lowest concentration of cryoconite is actually observed within the dark zone itself (Fig. 5a). Cryoconite only occupies a very small fraction of the total coverage $(1.6 \%$ maximum and $0.6 \%$ mean), which can be explained by the nature of the cryoconite material itself. The thread-like, filamentous structure of cyanobacteria enables them to entangle debris and facilitate the formation of granules. These granules absorb more solar radiation and melt down into the ice until they are in radiative and thermodynamic equilibrium ${ }^{30-32}$. Although this mechanism means that the cryoconite hole has a very low albedo value (mean $\alpha=0.10$ ) when observed from directly above, the hole occupies a relatively small area and is effectively hidden at non-zenith solar illumination resulting in an increase in mesoscale albedo ${ }^{20}$. Furthermore, cryoconite holes are often covered by an ice lid, caused by the refreezing of water that has filled the hole during negative net radiation conditions ${ }^{31}$. While thin frozen lids may undergo partial or complete ablation during the day, their higher albedo acts to further moderate the impact of cryoconite that they cover and render the holes indistinguishable from the adjacent ice surface (much to the dismay of many a field campaigner with sodden feet).

\section{Discussion}

The analysis presented here demonstrates that the dark zone has low fractional areas of surface water $(<1.0 \%)$, cryoconite holes $(<0.5 \%)$ and crevasses $(<0.2 \%)$. Instead, it appears that ice containing uniformly distributed impurities draped over a relatively flat surface are the primary agent responsible for the low (MOD10A1) albedo values observed during the melt season (Fig. 5a). Near the S6 AWS, from where the UAV was launched, Stibal et al. ${ }^{22}$ report that samples of distributed impurities consist of an abundance of ice algae (Fig. 4a), which are characterized by a grey/brown hue due to the brown-to-purple coloured pigments surrounding the algae chloroplasts ${ }^{24,33,34}$. Correlations between dust content and the abundance of microbes suggest that the melt-out of particulates may provide nutrients for surface ice algae to grow ${ }^{22,35}$ and indirectly control the extent of dark zone ${ }^{12}$. Further support for this hypothesis is provided by Tedstone et al. ${ }^{12}$ who argue that the large interannual variability in the extent of the dark zone, and its significant reduction in 2013 and 2015, demonstrates that bare ice albedo is not a consequence of summer ablation alone ${ }^{12}$. Instead, positive correlations between the dark zone extent and proxies for the availability of liquid water and nutrients are interpreted as evidence that blooms of surface ice algae control bare ice albedo across the dark zone. Any increase in temperature and/or liquid water production in the presence of dust promotes further colonization of surface algae yielding an increase in pigmented biomass and net albedo reduction ${ }^{24,36}$. The $12 \%$ expansion of the dark zone between 2000 and 2014 in western Greenland, corresponding with an increase in mean summer air temperature of $0.13^{\circ} \mathrm{C}$ per year over the same period ${ }^{11}$, provides further support for these ongoing processes.

While our results attest that the variation in the fractional area of supraglacial lakes, streams, crevasses and cryoconite do not significantly affect mesoscale albedo, they still play a secondary role in determining interannual and seasonal albedo variability. For example, supraglacial water may act to consolidate or distribute sediment and impurities across the ice sheet surface ${ }^{37}$. Moreover, a relatively small expansion in the spatial extent of surface water would have a disproportionate impact on mesoscale albedo and further amplify ablation. Melt rates at the base of supraglacial lakes and water bodies are double that of bare ice surfaces due to enhanced shortwave radiation absorption ${ }^{38,39}$. Atmospheric warming has been shown to increase the spatial extent and duration of ponded supraglacial water ${ }^{40,41}$. During years with higher summer temperatures, such as 2007, 2010 and 2012, supraglacial lakes formed earlier in the season and occupied a $40 \%$ larger area than in cooler summers ${ }^{40}$. It follows that increased storage of water in supraglacial lakes will play an important role in net albedo reduction across an expanding bare ice area in future.

Our analysis also demonstrates that crevasses reduce local (0.1-1 km) albedo, and hence any increase in crevasse extent will impact on mesoscale albedo patterns. Crevasses form due to localized concentration of tensile stresses which, due to highly variable subglacial conditions and longitudinal stress coupling, are spatially and temporally variable across the Greenland Ice Sheet ${ }^{16,42,43}$. In response to increased surface melt, GPS observations by van de Wal et al. ${ }^{44}$ report reduced net flow over the marginal zone of the K-transect, whereas Doyle et al. ${ }^{45}$ report persistent ice flow acceleration above the equilibrium line up to $140 \mathrm{~km}$ from the ice sheet margin in this same sector. Recent modelling ${ }^{46}$ and observations ${ }^{46,47}$ of new crevasses forming over $160 \mathrm{~km}$ from the western margin reveals that the ice sheet interior is also more dynamically sensitive to transient stress perturbations originating from downstream than a previous steady-state model suggests ${ }^{48}$. Regardless of ice dynamics, inland migration of the equilibrium line caused by atmospheric warming will drive increased bare ice extent, further exposing existing crevasses that were formerly snow and firn covered. Hence, surface crevasse extent will likely expand in future, resulting in mesoscale albedo reduction and enhanced surface absorption of incoming energy available for melt.

Finally, future spatial expansion of cryoconite does have the potential to significantly impact surface albedo. Hodson et al. ${ }^{49}$ showed that $53 \%$ of plot-scale $(0.01-0.5 \mathrm{~m})$ variation in albedo was correlated with the growth of cryoconite holes, and Chandler et al. ${ }^{21}$ report that the gradual seasonal reduction in albedo also correlates with an increase in cryoconite hole size and number. An increase in the extent of cryoconite holes may be caused by longer and warmer ablation seasons, which would increase the heat energy to the walls and base of the hole, leading to further melting and hole expansion ${ }^{31}$. On the other hand, an increase of meltwater may promote aggregation of distributed impurities and could have a surface cleaning effect, potentially raising the albedo of the surrounding bare ice ${ }^{20,31}$. The growth and development of 
cryoconite holes on mesoscale albedo is hence complex and still somewhat ambiguous.

In this study, we characterized the spatial variability of surface types across the western ablating margin of the ice sheet towards the end of the melt season when bare ice surfaces are most apparent. However, for much of the year (September to May), the ice sheet is snow-covered and it is likely that snow grain size and impurity concentration govern mesoscale albedo patterns across the K-transect and elsewhere during this period. Likewise, early melt-season albedo patterns are primarily governed by the relative proportions of snow and ice extent. Accurately determining snow melt and the timing of bare ice exposure has therefore been a priority for surface mass and energy balance models and the theoretical determinants of snow albedo and melt are relatively well established ${ }^{5,50}$. In contrast, few studies have investigated the albedo of the bare ice surface types that characterize the ablation zone and they have commonly been treated as temporal and spatial constants in surface melt models ${ }^{51-53}$.

The observed spatiotemporal variability in albedo across the ablation zone $\mathrm{e}^{54,55}$ has motivated a new generation of surface energy balance models that assimilate spatial patterns of albedo derived from MODIS data ${ }^{4,56,57}$. Across our $25 \mathrm{~km}$ survey transect, the MODIS-derived surface albedo pattern is dominated by variations in the extent of uniformly distributed impurities, a result that contradicts previous research attributing it to an increased occurrence of supraglacial water ${ }^{18}$. The source, processes and drivers of distributed impurities are yet to be unequivocally established, with some studies indicating a windblown origin, others revealing that they are derived from melt-out of englacial dust ${ }^{9-11}$. Recent research has promoted the concept of bioalbedo, which argues that the melt-out and release of
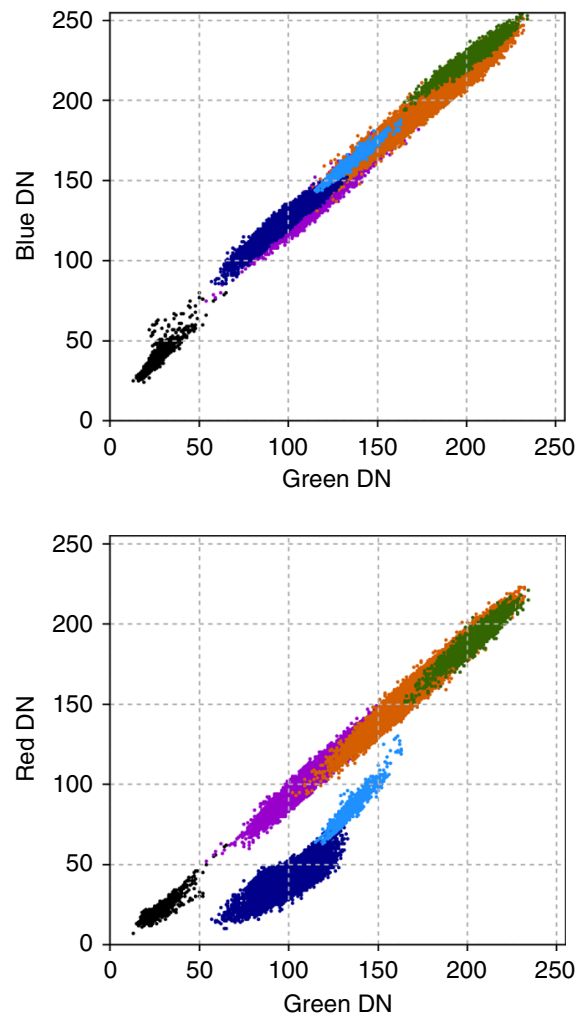

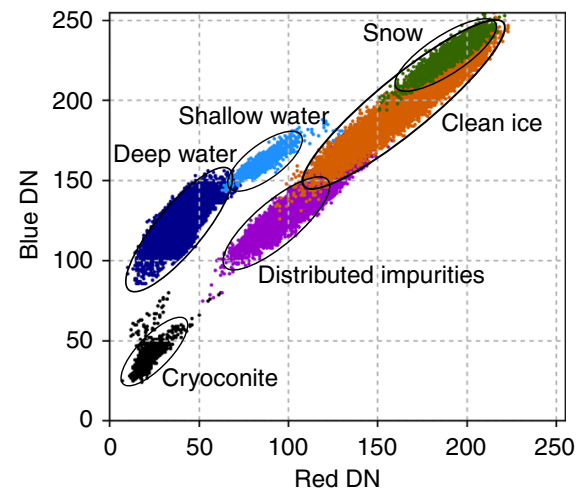

surface particulates and nutrients fertilizes pigmented ice surface algae, which drives albedo reduction over the duration of the melt season ${ }^{12,22}$. Further research though is required to determine how these factors combine to increase the spatial extent and concentration of pigmented surface algae, and their interaction with the availability of in situ and aeolian-derived nutrients, changing atmospheric forcing and enhanced ice melt and runoff.

\section{Methods}

MODIS albedo. Albedo patterns were determined from a MOD10A1 C6 broadband (spectral range of $300-3000 \mathrm{~nm}$ ) albedo product from the 8 August 2014 and available from the National Snow and Ice Data Center (NSIDC) ${ }^{58}$. MOD10A1 is gridded in a sinusoidal map projection and has a resolution of $\sim 500 \times 500 \mathrm{~m}$ or $0.25 \mathrm{~km}^{2}$. The value of each pixel represents the best single albedo observation in the day based on cloud cover and viewing and illumination angles ${ }^{59}$. We estimated that MOD10A1 has a root mean square difference (RMSD) of $7.0 \%$ in comparison to albedo measured by CNR1 or CNR4 thermopile pyranometers at the PROMICE/GAP automatic weather stations KAN-L, KAN-M and KAN-U between 2009 to $2014^{60}$. This compares well to Stroeve et al. ${ }^{59}$ who estimated an RMSD of $6.7 \%$.

UAV platform. Aerial imagery was acquired by a fixed-wing UAV identical to that used by Ryan et al. ${ }^{14,61,62}$ The UAV has a $2.1 \mathrm{~m}$ wingspan and is powered by a 10 $\mathrm{Ah}, 16.8 \mathrm{~V}$ LiPo battery pack which, with a total weight of $4 \mathrm{~kg}$, yields a $1 \mathrm{~h}$ endurance and $60 \mathrm{~km}$ range. The autonomous control system is based around an Arduino navigation and flight computer updated in real-time by a $10 \mathrm{~Hz}$ data stream comprising of a GPS, magnetometer, barometer and accelerometer. These data are logged along with a timestamp for each activation of the digital camera shutter which automatically triggers when a horizontal displacement threshold is exceeded. The UAV was hand launched on 8 August 2014 from a base camp at $67.08^{\circ} \mathrm{N}, 49.40^{\circ} \mathrm{W}$, located at the site of the Institute for Marine and Atmospheric Research (IMAU), University of Utrecht S6 automatic weather station. It was preprogrammed to carry out a $25 \mathrm{~km}$ survey across the Kangerlussuaq sector of the western Greenland Ice Sheet (Fig. 1). The Greenland Ice Mapping Project (GIMP) digital elevation model (DEM) ${ }^{63}$ was used during the selection of three-

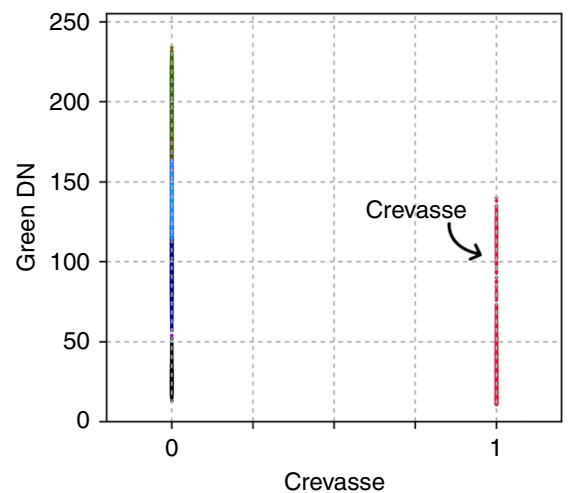

Fig. 7 Scatter-plots showing the key attributes of the seven surface types identified in this study. DN is digital number of the Sony NEX-5N calibrated RAW image. Deep and shallow supraglacial water is easily distinguishable because it has low reflectivity in the red band and forms a unique cluster in the feature space. Snow, clean ice, ice containing distributed impurities and cryoconite form another cluster and are distinguishable because they reflect different proportions of RGB visible wavelengths 
dimensional waypoints to ensure the UAV maintained a constant altitude of $350 \mathrm{~m}$ above the surface during the autonomous sorties. On return from the sortie, the UAV was manually landed into a $10 \times 5 \mathrm{~m}$ net.

Digital imagery. Digital imagery was acquired by a Sony NEX-5N digital camera vertically mounted inside the front of the airframe. The camera has a $16 \mathrm{~mm}$ fixed focus lens ( 53.1 by $73.7^{\circ}$ field of view) yielding an image footprint of $\sim 525 \times 350 \mathrm{~m}$ during the autonomous sortie. The width of each image is approximately similar to the pixel footprint of MODIS. The camera was preset with a fixed shutter speed of $1 / 1000 \mathrm{~s}$, ISO 100 and F-stop of 8 , and triggered every $35 \mathrm{~m}$ to provide a $90 \%$ forward image overlap. The relatively fast shutter speed minimizes image blur while the low ISO and F-number ensures maximum image quality where even the brightest surfaces do not saturate the image. The camera was set to record the images in RAW format, an image format that contains minimally processed data from the camera's sensor. During the survey, 2000 RAW images were acquired at the camera's maximum $(4912 \times 3264$ pixels $)$ resolution which, once the images were corrected for barrel, or geometric, distortion, equates to a ground sampling distance of $\sim 11 \mathrm{~cm}$.

Orthomosaic and DEM generation. The $\mathrm{R}(\mathrm{ed}) / \mathrm{G}($ reen $) / \mathrm{B}(\mathrm{lue})$ images were used to produce an orthomosaic and DEM using Agisoft PhotoScan Pro (http://www. agisoft.com/) following the processing sequence described by Ryan et al. ${ }^{60}$ The images were georeferenced by providing latitude, longitude and altitude data recorded by the flight controller. The orthomosaic was produced in the software's 'mosaic' mode, meaning that pixels in the centre of the images were preferentially used to provide the output pixel value. The orthomosaic and DEM were nearest neighbour resampled to a ground resolution of $15 \mathrm{~cm}$ and $50 \mathrm{~cm}$, respectively. We divided the orthomosaic into sixty $0.25 \mathrm{~km}^{2}$ segments and each segment was assigned a MOD10A1 value.

Surface classification. The fractional area of each surface type was calculated by dividing the number of pixels of each surface type by the total number of pixels in each orthomosaic segment. The number of pixels of each surface type was estimated using a supervised k-NN classification from the scikit-learn Python mod$\mathrm{ule}^{64}$. The pixels were classified using a majority vote based on the Euclidean distance to five equally weighted nearest neighbours (Fig. 7). The k-NN was manually trained with seven distinct and visually identified surfaces found in the orthomosaic: (i) clean ice, (ii) ice containing uniformly distributed impurities, (iii) deep water, (iv) shallow water, (v) cryoconite either in holes or fluvial deposits, (vi) crevasses and (vii) snow. The training samples of the surface types were manually digitized from 10 orthomosaic segments based on RGB brightness and a layer that specified whether or not the pixel was situated within a crevasse or fracture. This roughness layer was determined by calculating the residual between the original $50 \mathrm{~cm}$ DEM subtracted from a $30 \mathrm{~m}$ Gaussian-smoothed DEM. Negative anomalies with a vertical displacement $>1 \mathrm{~m}$ were identified as crevasses. Small cracks and fractures were detected on the basis of sharp RGB contrast, and were discriminated using an edge detector algorithm ${ }^{65}$. Pixels within $2 \mathrm{~m}$ of a linear feature were also identified as crevasses.

The efficacy of the k-NN classifier was evaluated by comparison with independently digitized surface types in three orthomosaic segments, at the centre and extreme ends of the transect. We found that $92 \%$ of the pixels were classified accurately. The k-NN classified crevasses with an accuracy of $88 \%$ and performed better for deep and shallow water (96\%) than for cryoconite, ice containing distributed impurities, clean ice and snow $(90 \%)$. The classification of supraglacial water is relatively accurate because water has low reflectance in the red band and forms a unique cluster in the feature space (Fig. 7). The performance of the k-NN for clean ice and ice containing distributed impurities is less accurate (90\%) because these surfaces reflect the RGB visible bands in similar relative proportions and the surface classes overlap in the feature space (Fig. 7). Misclassification could also be caused by shadows, especially in segments with steep topography (eg, Fig. 6b). Shadows increase the proportions of the surface classified as ice containing distributed impurities and/or cryoconite. Accounting for shadows would reduce the proportion of ice containing distributed impurities in the crevassed zone (Fig. 6b) and subsequently increase their variation across the transect. This would make the impact of distributed impurities on the mesoscale albedo variability, and the conclusions of this study, more significant. Finally, we used PCR to explore the dominant modes of surface type variation along the transect and assess which surface type, or set of surface types, best correlate with mesoscale albedo variability, as represented by MOD10A1. Linear regression was used to yield the correlation coefficients between the principle component scores and MOD10A1 albedo.

Estimating albedo of digital image pixels. An estimate for the albedo $(\alpha)$ of each surface type was obtained from the UAV digital imagery. An explicit description of this method can be found in Ryan et al. ${ }^{14}$, but we briefly summarize it here. Firstly, the RAW digital numbers of each proprietary Sony RAW image were preserved by converting to a 16-bit TIFF image using dcraw (http://cybercom.net/ dcoffin/ dcraw/). A vignette correction mask was universally applied to compensate for image and lens distortion due to edge effects which were as high as $17.6 \%$ at the corners of some images. The correction mask was calculated from the mean vignette of all images acquired at nadir during the survey period. Barrel distortion was corrected using ImageMagick (http://www.imagemagick.org/), which utilized the coefficients stored in the image's ancillary metadata also known as exchangeable image file format data.

We then corrected the images for changing illumination conditions during the survey using downward irradiance measured by a ground-based upward facing Apogee SP-110 pyranometer. To do this, images of a $25 \times 25 \mathrm{~cm}$ Teflon white reference target were acquired every $10 \mathrm{~min}$ using the UAV digital camera from the ground. The relationship between the mean RGB DNs of the white reference target and the downward irradiance recorded by the upward facing pyranometer were used to construct a calibration curve using a linear least squares regression $\left(R^{2}=\right.$ $0.96)$. The ratio of reflected radiation recorded by the camera and the downward radiation estimated from the calibration curve enabled the illumination-corrected reflectance of each pixel to be defined.

Since snow and ice are non-Lambertian surfaces, a nadir measurement of reflectance underestimates albedo by between 1 and $5 \%$ in the visible band ${ }^{66}$. The illumination-corrected images were therefore calibrated again by multiplying the image pixel numbers by a factor calculated by dividing the mean pixel value of the illumination-corrected image by the albedo recorded by upward and downward facing Apogee SP-110 pyranometers mounted on the UAV. Ryan et al. ${ }^{14}$ found that albedo determined using this method has an accuracy of $\pm 5 \%$ over ice sheet surfaces typically found in the ablation zone.

Data availability. The MODIS (MOD10A1) albedo data are available from the National Snow and Ice Data Center (NSIDC) at http://nsidc.org/data/MOD10A1. The UAV images are archived in the PANGAEA repository: https://doi.pangaea. de/10.1594/PANGAEA.885798.

Received: 21 June 2017 Accepted: 7 February 2018 Published online: 14 March 2018

\section{References}

1. Box, J. E. et al. Changes to Arctic land ice. In Snow, Water, Ice and Permafrost in the Arctic (SWIPA) 137-168 (Arctic Monitoring and Assessment Programme (AMAP), Oslo, Norway, 2017).

2. Hanna, E. et al. Ice-sheet mass balance and climate change. Nature 498, 51-59 (2013).

3. Enderlin, E. M. et al. An improved mass budget for the Greenland ice sheet. Geophys. Res. Lett. 41, 866-872 (2014).

4. van den Broeke, M. R. et al. On the recent contribution of the Greenland ice sheet to sea level change. Cryosphere 10, 1933-1946 (2016).

5. Gardner, A. S. \& Sharp, M. J. A review of snow and ice albedo and the development of a new physically based broadband albedo parameterization. $J$. Geophys. Res. Earth Surf. 115, 1-15 (2010).

6. van den Broeke, M. R. et al. Partitioning of melt energy and meltwater fluxes in the ablation zone of the west Greenland ice sheet. Cryosphere 2, 179-189 (2008).

7. Mikkelsen, A. B. et al. Extraordinary runoff from the Greenland ice sheet in 2012 amplified by hypsometry and depleted firn retention. Cryosphere 10, 1147-1159 (2016)

8. Knap, W. H. \& Oerlemans, J. The surface albedo of the Greenland ice sheet: satellite-derived and in situ measurements in the Søndre Strømfjord area during the 1991 melt season. J. Glaciol. 42, 364-374 (1996).

9. Wientjes, I. G. M. \& Oerlemans, J. An explanation for the dark region in the western melt zone of the Greenland ice sheet. Cryosphere 4, 261-268 (2010).

10. Wientjes, I. et al. Carbonaceous particles reveal that Late Holocene dust causes the dark region in the western ablation zone of the Greenland ice sheet. J. Glaciol. 58, 787-794 (2012).

11. Shimada, R., Takeuchi, N. \& Aoki, T. Inter-annual and geographical variations in the extent of bare ice and dark ice on the Greenland Ice Sheet derived from MODIS satellite images. Front. Earth Sci. 4, 1-10 (2016).

12. Tedstone, A. J. et al. Dark ice dynamics of the south-west Greenland Ice Sheet. Cryosphere 11, 2491-2506 (2017)

13. Moustafa, S. E. et al. Multi-modal albedo distributions in the ablation area of the southwestern Greenland Ice Sheet. Cryosphere 9, 1-11 (2015).

14. Ryan, J. C. et al. Attribution of Greenland's ablating ice surfaces on ice sheet albedo using unmanned aerial systems. The Cryosphere Discuss. 1-23. https://doi.org/10.5194/tc-2016-204 (2016).

15. Ryan, J. C. et al. Derivation of high spatial resolution albedo from UAV digital imagery: application over the Greenland Ice Sheet. Front. Earth Sci. 5, 40 (2017)

16. Colgan, W. et al. An increase in crevasse extent, West Greenland: Hydrologic implications. Geophys. Res. Lett. 38, L18502 (2011).

17. Colgan, W. et al. Glacier crevasses: observations, models and mass balance implications. Rev. Geophys. 54, 119-161 (2016). 
18. Greuell, W. Melt-water accumulation on the surface of the Greenland Ice Sheet: effect on albedo and mass balance. Geogr. Ann. A Phys. Geogr. 82, 489-498 (2000).

19. Smith, L. C. et al. Efficient meltwater drainage through supraglacial streams and rivers on the southwest Greenland ice sheet. Proc. Natl Acad. Sci. USA 112, 1001-1006 (2015).

20. Bøggild, C. E., Brandt, R. E., Brown, K. J. \& Warren, S. G. The ablation zone in northeast Greenland: ice types, albedos and impurities. J. Glaciol. 56, 101-113 (2010).

21. Chandler, D. M., Alcock, J. D., Wadham, J. L., Mackie, S. L. \& Telling, J. Seasonal changes of ice surface characteristics and productivity in the ablation zone of the Greenland Ice Sheet. Cryosphere 9, 487-504 (2015).

22. Stibal, M. et al. Algae drive enhanced darkening of bare ice on the Greenland ice sheet. Geophys. Res. Lett. 44, 11463-11471 (2017).

23. Stibal, M. et al. Organic matter content and quality in supraglacial debris across the ablation zone of the Greenland ice sheet. Ann. Glaciol. 51, 1-8 (2010).

24. Yallop, M. L. et al. Photophysiology and albedo-changing potential of the ice algal community on the surface of the Greenland ice sheet. ISME J. 6, 2302-2313 (2012).

25. Dumont, M. et al. Contribution of light-absorbing impurities in snow to Greenland's darkening since 2009. Nat. Geosci. 7, 509-512 (2014).

26. Keegan, K. M., Albert, M. R., McConnell, J. R. \& Baker, I. Climate change and forest fires synergistically drive widespread melt events of the Greenland Ice Sheet. Proc. Natl Acad. Sci. USA 111, 7964-7967 (2014).

27. Wientjes, I. G. M., Van de Wal, R. S. W., Reichart, G. J., Sluijs, A. \& Oerlemans, J. Dust from the dark region in the western ablation zone of the Greenland ice sheet. Cryosphere 5, 589-601 (2011).

28. Pfeffer, W. T. \& Bretherton, C. S. The effect of crevasses on the solar heating of a glacier surface. In Proc. of the Vancouver Symposium, August 1987, IAHS Publ. no. 170, 191-205 (IAHS Publications, Wallingford, UK, 1987).

29. Cathles, L. M., Abbot, D. S., Bassis, J. N. \& MacAyeal, D. R. Modeling surfaceroughness/solar-ablation feedback: application to small-scale surface channels and crevasses of the Greenland Ice Sheet. Ann. Glaciol. 52, 99-108 (2011).

30. Langford, H., Hodson, A., Banwart, S. \& Bøggild, C. The microstructure and biogeochemistry of Arctic cryoconite granules. Ann. Glaciol. 51, 87-94 (2010).

31. Cook, J., Edwards, A., Takeuchi, N. \& Irvine-Fynn, T. Cryoconite: the dark biological secret of the cryosphere. Prog. Phys. Geogr. 40, 66-111 (2015).

32. Takeuchi, N. Optical characteristics of cryoconite (surface dust) on glaciers: the relationships between light absorbency and the property of organic matter contained in the cryoconite. Ann. Glaciol. 34, 409-414 (2002).

33. Remias, D. et al. Characterization of an UV- and VIS-absorbing, purpurogallin-derived secondary pigment new to algae and highly abundant in Mesotaenium berggrenii (Zygnematophyceae, Chlorophyta), an extremophyte living on glaciers. FEMS Microbiol. Ecol. 79, 638-648 (2012)

34. Stibal, M., Šabacká, M. \& Žárský, J. Biological processes on glacier and ice sheet surfaces. Nat. Geosci. 5, 771-774 (2012).

35. Stibal, M. et al. Microbial abundance in surface ice on the Greenland Ice Sheet. Front. Microbiol. 6, 225 (2015)

36. Lutz, S. et al. The biogeography of red snow microbiomes and their role in melting arctic glaciers. Nat. Commun. 7, 1-9 (2016).

37. Ryser, C. et al. Cold ice in the ablation zone: Its relation to glacier hydrology and ice water content. J. Geophys. Res. Earth Surf. 118, 693-705 (2013).

38. Lüthje, M., Pedersen, L. T., Reeh, N. \& Greuell, W. Modelling the evolution of supraglacial lakes on the west Greenland ice-sheet margin. J. Glaciol. 52, 608-618 (2006).

39. Tedesco, M. \& Steiner, N. In-situ multispectral and bathymetric measurements over a supraglacial lake in western Greenland using a remotely controlled watercraft. Cryosphere 5, 445-452 (2011).

40. Fitzpatrick, A. A. W. et al. A decade (2002-2012) of supraglacial lake volume estimates across a land-terminating margin of the Greenland Ice Sheet. The Cryosphere Dicuss. 7, 1383-1414 (2014).

41. Leeson, A. et al. Supraglacial lakes on the Greenland ice sheet advance inland under warming climate. Nat. Clim. Chang. 5, 51-55 (2015).

42. Hubbard, A. L., Blatter, H., Nienow, P., Mair, D. \& Hubbard, B. Comparison of a three-dimensional model for glacier flow with field data from Haut Glacier d' Arolla, Switzerland. J. Glaciol. 44, 368-378 (1998).

43. van der Veen, C. J. Crevasses on glaciers. Polar Geogr. 23, 1-33 (1999).

44. van de Wal, R. S. W. et al. Large and rapid melt-induced velocity changes in the ablation zone of the Greenland Ice Sheet. Science 321, 111-113 (2008)

45. Doyle, S. H. et al. Persistent flow acceleration within the interior of the Greenland ice sheet. Geophys. Res. Lett. 41, 899-905 (2014).

46. Christoffersen, P., Bougamont, M., Hubbard, A., Doyle, S. \& Grigsby, S. Tensile shock triggers cascading lake drainage on the Greenland Ice Sheet. Nat. Commun. https://doi.org/10.1038/s41467-018-03420-8 (2018).
47. Scheick, J. Investigating Greenland Crevasses at Raven Camp. Field Notes, Polar Field Services Newsletter, http://www.polarfield.com/blog/blog/ investigating-greenland-crevasses-raven-camp. Accessed 25 May 2014 (2012).

48. Poinar, K. et al. Limits to future expansion of surface-melt-enhanced ice flow into the interior of western Greenland. Geophys. Res. Lett. 42, 1800-1807 (2015).

49. Hodson, A. et al. A glacier respires: quantifying the distribution and respiration $\mathrm{CO}_{2}$ flux of cryoconite across an entire Arctic supraglacial ecosystem. J. Geophys. Res. 112, G04S36 (2007).

50. Wiscombe, W. J. \& Warren, S. G. A model for the spectral albedo of snow. I: Pure snow. J. Atmos. Sci. 37, 2712-2733 (1980).

51. Zuo, Z. \& Oerlemans, J. Modelling albedo and specific balance of the Greenland ice sheet: calculations for the Sondre Strømfjord transect. J. Glaciol. 42, 305-316 (1996).

52. Hock, R. Glacier melt: a review of processes and their modelling. Prog. Phys Geogr. 29, 362-391 (2005).

53. Alexander, P. M. et al. Assessing spatio-temporal variability and trends in modelled and measured Greenland Ice Sheet albedo (2000-2013). Cryosphere 8, 2293-2312 (2014).

54. Tedesco, M. et al. The role of albedo and accumulation in the 2010 melting record in Greenland. Environ. Res. Lett. 6, 014005 (2011).

55. Box, J. E. et al. Greenland ice sheet albedo feedback: thermodynamics and atmospheric drivers. Cryosphere 6, 821-839 (2012).

56. van Angelen, J. H. et al. Sensitivity of Greenland Ice Sheet surface mass balance to surface albedo parameterization: a study with a regional climate model. Cryosphere 6, 1175-1186 (2012).

57. Langen, P. L. et al. Liquid water flow and retention on the Greenland Ice Sheet in the regional climate model HIRHAM5: local and large-scale impacts. Front. Earth Sci. 4, 110 (2017)

58. Hall, D. K. \& Riggs, G. A. MODIS/Terra Snow Cover Daily L3 Global $500 m$ Grid, Version 6 (NASA National Snow and Ice Data Center Distributed Active Archive Center, Boulder, 2016)

59. Stroeve, J. C., Box, J. E. \& Haran, T. Evaluation of the MODIS (MOD10A1) daily snow albedo product over the Greenland ice sheet. Remote Sens. Environ. 105, 155-171 (2006).

60. van As, D. et al. Large surface meltwater discharge from the Kangerlussuaq sector of the Greenland ice sheet during the record-warm year 2010 explained by detailed energy balance observations. Cryosphere 6, 199-209 (2012).

61. Ryan, J. C. et al. UAV photogrammetry and structure from motion to assess calving dynamics at Store Glacier, a large outlet draining the Greenland ice sheet. Cryosphere 9, 1-11 (2015).

62. Ryan, J. C. et al. How robust are in situ observations for validating satellitederived albedo over the dark zone of the Greenland Ice Sheet? Geophys. Res. Lett. 44, 6218-6225 (2017).

63. Howat, I. M., Negrete, A. \& Smith, B. E. The Greenland Ice Mapping Project (GIMP) land classification and surface elevation data sets. Cryosphere $\mathbf{8}$ 1509-1518 (2014)

64. Pedregosa, F., Weiss, R. \& Brucher, M. Scikit-learn: machine learning in Python. J. Mach. Learn. Res. 12, 2825-2830 (2011).

65. Canny, J. A computational approach to edge detection. IEEE Trans. Pattern Anal. Mach. Intell. 8, 679-698 (1986).

66. Knap, W. H. \& Reijmer, C. H. Anisotropy of the reflected radiation field over melting glacier ice: measurements in Landsat TM bands 2 and 4. Remote Sens. Environ. 65, 93-104 (1998).

\section{Acknowledgements}

J.C.R. was funded by an Aberystwyth University Doctoral Career Development Scholarship (DCDS) and is currently funded by the NASA Cryosphere Program grant NNX14AH93G. The field camp, logistics and J.B. were supported by the Dark Snow Project (http://www.darksnow.org/). We also gratefully acknowledge the UK Natural Environment Research Grants NE/H024204/1 and NE/G005796/1, the Aberystwyth University Research Fund and the Danish Villum Young Investigator Programme grant VKR 023121 awarded to M.S. A.H. acknowledges support from the Centre for Arctic Gas Hydrate, Environment and Climate, funded by the Research Council of Norway through its Centres of Excellence (grant 223259). J.C. acknowledges a Rolex Award for Enterprise and L.C.S. acknowledges the NASA Cryosphere Program grant NNX14AH93G. The automatic weather stations used to validate the MODIS albedo data were funded and installed by the Greenland Analogue Project (GAP) and maintained by the Geological Survey of Denmark and Greenland (GEUS). We thank Peter Sinclair and Gabriel Warren for their assistance in the field and our three reviewers.

\section{Author contributions}

J.C.R. and A.H. designed, tested and built the UAVs. A.H. and J.B. were the project PIs and J.B. provided UAV onboard pyranometers and data logger. J.C.R. and J.B. 
programmed and deployed the UAV. J.C.R. analysed the data and wrote the original manuscript with A.H. who also provided direction/supervision. K.C. provided the ground photographs used for qualitative assessment of surface types. A.H., M.S., J.B., J.C., T.D.I.-F., L.C.S. and K.C. provided conceptual and technical advice and contributed to data interpretation. All authors commented and critically revised the manuscript.

\section{Additional information}

Competing interests: The authors declare no competing interests.

Reprints and permission information is available online at http://npg.nature.com/ reprintsandpermissions/

Publisher's note: Springer Nature remains neutral with regard to jurisdictional claims in published maps and institutional affiliations. (c) (i) Open Access This article is licensed under a Creative Commons Attribution 4.0 International License, which permits use, sharing, adaptation, distribution and reproduction in any medium or format, as long as you give appropriate credit to the original author(s) and the source, provide a link to the Creative Commons license, and indicate if changes were made. The images or other third party material in this article are included in the article's Creative Commons license, unless indicated otherwise in a credit line to the material. If material is not included in the article's Creative Commons license and your intended use is not permitted by statutory regulation or exceeds the permitted use, you will need to obtain permission directly from the copyright holder. To view a copy of this license, visit http://creativecommons.org/ licenses/by/4.0/.

(C) The Author(s) 2018 